\title{
FDA Device Component Code Hierarchy
}

National Cancer Institute

\section{Source}

National Cancer Institute. FDA Device Component Code Hierarchy. NCI Thesaurus. Code C54577.

Terminology used for device components or accessories in safety reports and FDA $\mathrm{CDRH}$ documents during both pre and post approval periods of device development and usage. 